\title{
Effect of a sport-for-health intervention (SmokeFree Sports) on smoking-related intentions and cognitions among 9-10 year old primary school children: a controlled trial
}

Ciara E. McGee ${ }^{1 *}$, Joanne Trigwell ${ }^{2}$, Stuart J. Fairclough ${ }^{3,6}$, Rebecca C. Murphy ${ }^{4}$, Lorna Porcellato', Michael Ussher ${ }^{5}$ and Lawrence Foweather ${ }^{4}$

\begin{abstract}
Background: Preventing children from smoking is a public health priority. This study evaluated the effects of a sport-for-health smoking prevention programme (SmokeFree Sports) on smoking-related intentions and cognitions among primary school children from deprived communities.

Methods: A non-randomised-controlled trial targeted 9-10 year old children from Merseyside, North-West England. 32 primary schools received a programme of sport-for-health activities over 7 months; 11 comparison schools followed usual routines. Data were collected pre-intervention (T0), and at 8 months (T1) and one year post-intervention (T2). Smoking-related intentions and cognitions were assessed using an online questionnaire. Intervention effects were analysed using multi-level modelling (school, student), adjusted for baseline values and potential confounders. Mixed-sex focus groups $(n=18)$ were conducted at T1.

Results: 961 children completed all assessments and were included in the final analyses. There were no significant differences between the two study groups for non-smoking intentions (T1: $\beta=0.02,95 \%$ $\mathrm{Cl}=-0.08-0.12 ; \mathrm{T} 2: \beta=0.08,95 \% \mathrm{Cl}=-0.02-0.17)$ or for cigarette refusal self-efficacy (T1: $\beta=0.28,95 \%$ $\mathrm{Cl}=-0.11-0.67 ; \mathrm{T} 2: \beta=0.23,95 \% \mathrm{Cl}=-0.07-0.52)$. At $\mathrm{T} 1$ there was a positive intervention effect for cigarette refusal self-efficacy in girls ( $\beta=0.72,95 \% \mathrm{Cl}=0.21-1.23$ ). Intervention participants were more likely to 'definitely' believe that: 'it is not safe to smoke for a year or two as long as you quit after that' (RR $=1.19,95 \% \mathrm{Cl}=1.07-1.33$ ), 'it is difficult to quit smoking once started' ( $R R=1.56,95 \% \mathrm{Cl}=1.38-1.76)$, 'smoke from other peoples' cigarettes is harmful' $(\mathrm{RR}=1.19,95 \% \mathrm{Cl}=1.20-2.08)$, 'smoking affects sports performance' ( $\mathrm{RR}=1.73,95 \% \mathrm{Cl}=1.59-1.88)$ and 'smoking makes 'no difference' to weight' ( $R R=2.13,95 \% \mathrm{Cl}=1.86-2.44)$. At T2, significant between-group differences remained just for 'smoking affects sports performance' (RR $=1.57,95 \% \mathrm{Cl}=1.43-1.72)$. Focus groups showed that SFS made children determined to remain smoke free and that the interactive activities aided children's understanding of smoking harms.

(Continued on next page)
\end{abstract}

\footnotetext{
* Correspondence: c.e.mcgee@ljmu.ac.uk

${ }^{1}$ Centre for Public Health, Liverpool John Moores University, Henry Cotton

Campus, 15-21 Webster Street, Liverpool L3 2AT, UK

Full list of author information is available at the end of the article
} 
(Continued from previous page)

Conclusion: SFS demonstrated short-term positive effects on smoking attitudes among children, and cigarette refusal self-efficacy among girls. Although no effects were observed for non-smoking intentions, children said that SFS made them more determined not to smoke. Most children had strong intentions not to smoke; therefore, smoking prevention programmes should perhaps target early adolescents, who are closer to the age of smoking onset.

Keywords: Smoking, Prevention, Children, Intervention, School-based

\section{Background}

Smoking is an addiction often initiated in childhood, with approximately 207,000 children taking up smoking each year in the UK [1]. The earlier a child starts to smoke, the higher their chances of becoming a regular smoker and the more difficult it becomes to quit [2]. Early onset of smoking and persisting in the habit in adulthood increases the risk of developing lung cancer and other smoking-related diseases [3, 4]. Preventing smoking uptake in children by de-normalising tobacco use is therefore a key public health priority for the UK Government [5], which is aiming for a tobacco-free generation by 2025 [6]. Although only $0.3 \%$ of $8-10$ year old UK primary school children have ever smoked [7], some children develop intentions to start smoking [8]. Behavioural intentions to smoke are worth paying special attention to as they are theorised to be the first step in smoking initiation [9]. Intentions to smoke may be explained by individual smoking-related cognitions such as attitudes towards smoking and cigarette refusal selfefficacy [10-12]. Since children living in socially deprived areas have a high intention to smoke [13] and harbour misconceptions about the harms of smoking [14], implementing a smoking prevention intervention in primary school may prevent children from starting to smoke.

Schools are considered an appropriate setting for smoking prevention because they can provide an efficient means of reaching large numbers of children [15] and provide an opportunity to 'set' healthy and enduring patterns of behaviour [16, 17]. Consequently, numerous school-based smoking prevention programmes have been developed and implemented over the last decade to discourage smoking uptake and deter regular use $[18,19]$. Previous interventions have predominantly targeted adolescents, whilst programmes that have been developed for primary school aged children have been implemented outside the UK $[18,19]$. Waiting until secondary school to intervene with smoking prevention programmes can be too late, since by then adolescents may have developed deep rooted smoking expectancies and norms [20-22] and, for some the behaviour is already underway ( $8 \%$ of 15 year olds smoke) [23].

Sport-for-health programmes use sport as a mechanism to promote health and prevent disease [24-27].
Interventions typically use participatory approaches like game-based learning and activities with sport coaches, who represent important role models for youth, to transmit health promotion messages and positively shape attitudes $[28,29]$. The use of sport as an educational platform for tobacco control has previously been trialled in the US and Canada with initiatives such as Tobacco Free Sports [30], Tobacco Free Athletes [31] and Play, Live, Be Tobacco Free [32]. Sport-for-health interventions have several potential benefits over traditional classroom-based smoking prevention education approaches. First, participation in physical activity improves health not only directly but also through its protective effect against smoking initiation in youth [33, 34]. Second, given that all primary school children are required to participate in physical education, this lesson could provide a forum to integrate smoking education messages within the primary school curriculum. Third, the use of sport as a smoking prevention strategy encourages active engagement with the intervention as well as interactions with other pupils and teaching staff, and is consistent with National Institute for Health and Care Excellence (NICE) recommendations [35] to deliver interactive and participatory smoking prevention interventions. Finally, integrating physical activity into the learning process may enable children to efficiently retain and retrieve learned information [28, 36-38]. To the authors' knowledge, no published study has evaluated the use of sport-for-health programmes for smoking prevention in the UK.

SmokeFree Sports (SFS) was a sport-for-health smoking prevention intervention for youth in Liverpool, which is one of the most deprived communities in England [39] where addressing inequalities in tobacco use is a public health priority. Established in October 2010, SFS was commissioned as part of the 'SmokeFree Liverpool' public health campaign. The intervention was designed in accordance with the NICE guidance [35] and the Medical Research Council (MRC) framework for developing and evaluating complex interventions [40]. Phase one of SFS (February-June 2011) was a community feasibility trial in five youth clubs, which received 12 weeks of coaching activities (dance, dodge-ball and boxing) delivered by trained sports coaches $[29,41]$. A 
formative evaluation demonstrated that the intervention helped to prevent youth from initiating smoking and had positive benefits on their attitudes and knowledge about smoking [29, 41]. However, coaches reported challenges associated with its delivery in youth clubs and recommended that the intervention be trialled in schools. Phase two (February-April 2012) therefore examined the feasibility of a six week intervention in three primary schools [42]. Trained coaches delivered twelve sessions of sports (football and dance). Similar positive benefits for children were observed, whilst teachers and coaches perceived SFS to be acceptable for smoking prevention education [42]. These promising results led to the development of a larger, controlled trial to investigate the effectiveness of SFS in Liverpool primary schools.

The present study evaluated whether SFS, a sportfor-health smoking prevention intervention, is effective in increasing non-smoking intentions in 9-10 year old primary school children from Liverpool, immediately post-intervention and at a follow-up one year later. Secondary aims were to investigate the impact of the intervention on children's attitudes towards smoking and cigarette refusal self-efficacy, termed smoking-related cognitions hereafter. The study also investigated whether sex moderated the intervention effects as differences in cognitive vulnerability towards smoking have been found between preadolescent boys and girls [14]. In addition, focus groups with children were conducted to produce more complete knowledge to inform interpretations of intervention effectiveness. Since sport-for-health interventions are an emergent area of health promotion research where evaluations are sparse and/or have lacked methodological rigour $[26,43]$, it is recognised that rigorous evaluations of interventions are needed to inform future practice and procedures [25].

\section{Methods}

\section{Study design}

A school-based non-randomised controlled trial was conducted to evaluate the effect of a sport-for-health smoking prevention intervention, SmokeFree Sports on children's intentions (not) to smoke and smoking-related cognitions. Due to funding requirements, SFS was offered to all primary schools within the Liverpool City Council administrative boundaries and therefore an a priori sample size calculation was not undertaken. Schools within Knowsley, another metropolitan borough in Merseyside with similar characteristics to Liverpool in terms of adult smoking rates (Liverpool: 24.2 \%; Knowsley: 27.6 \%) [44], deprivation levels [45] and ethnic composition [46], were recruited as comparison schools. For logistical reasons, it was not possible to blind the research team to the groupallocation. Schools were clustered into two groups:

1. Intervention group (Liverpool): Schools received their usual smoking-related education plus SFS

2. Comparison group (Knowsley): Schools received their usual smoking education only

A schematic overview of the intervention and evaluation components is shown in Fig. 1. Data collection occurred over 20 months with measurements at baseline (T0, September and October 2012) and post-intervention (T1, June 2013) whilst children were in Year 5 of primary school, and at one year after the intervention had finished (T2, June 2014; Year 6 of primary school). Ethical approval for the study was granted by Liverpool John Moores University Research Ethics Committee (12/SPS/038).

\section{Participants and recruitment}

In September 2012, all eligible primary schools (mainstream state schools; $n=154)$, from Liverpool $(n=104)$
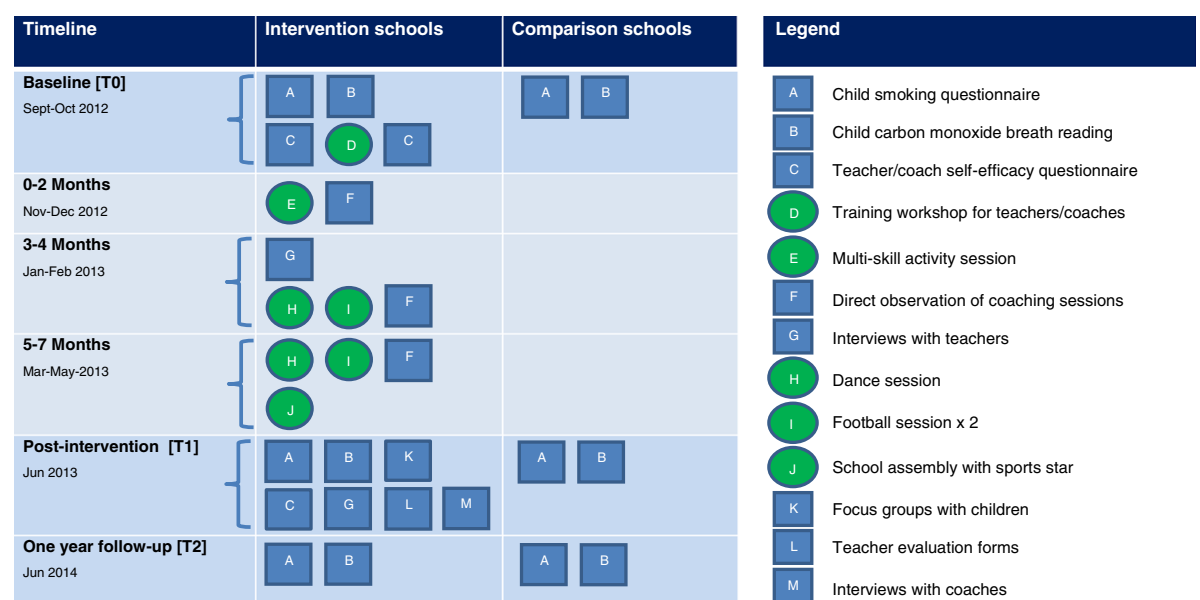

Fig. 1 Schematic overview of SmokeFree Sports intervention and evaluation components 
and Knowsley $(n=50)$, were invited to participate in the study via email, post and telephone. Once schools had given written informed consent to participate in the study, all Year 5 children (aged 9-10 years; $n=1393$ ) were invited to take part. Parents/guardians received a letter containing a parent and child information sheet and opt-out form. Parents/guardians were given contact information for the research team to discuss the project and could opt their child out of the study by telephone or by signing and returning the opt-out form. At data collection, children were given a verbal explanation of the study and asked to give signed assent. Children could withdraw from the research study at any time.

\section{Intervention}

The SFS intervention was delivered during school hours in Liverpool primary schools between October 2012 and May 2013. The intervention focused on smoking prevention and therefore Year 5 children (aged 9-10) were identified as an important cohort to target. Further, NICE [35] guidelines postulate that smoking prevention efforts would be most effective if they began in primary school.

A detailed description of the SFS intervention has been published elsewhere [47, 48]. Briefly, the socioecological model [49] and cognitive theories including the Health Belief Model [50], Theory of Planned Behaviour [9] and Social Cognitive/Learning [51], guided the intervention design. The intervention aimed to implement a programme of smoking prevention actions through fun, participatory and interactive sports activities delivered by teachers and coaches. Intervention components included provision of professional development training, a training manual including 10 session plans, five coaching sessions delivered by SFS coaches, a school assembly with a local sports star, sports equipment as incentives for teachers to deliver and evaluate a minimum of five SFS sessions, a smoke free pledge for children to sign, and incentives for children for participating in the research (SFS water bottle, drawstring bag and pen). Behaviour change techniques [52] used with children included a behavioural contract (smoke free pledge); social support, advice, verbal persuasion and positive reinforcement (from peers, teachers and coaches) on remaining never smokers; information and salience of the social, emotional and health consequences of smoking; an exploration of the pros and cons of smoking; awareness raising of regret children will feel if they smoke; social comparisons with peers to dispel myths that smoking is normative; modelling of never smoking (from elite athletes); cigarette refusal rehearsals, and the promotion of physical activity as a positive distraction to smoking.

\section{Comparison group}

Children in the comparison group were requested to follow their usual smoking education. It is not mandatory to address smoking education in Key Stage 2 (pupils aged 7-11) of the UK National Curriculum [53], and it is at schools' discretion to include the topic as part of Personal Social Health and Economic education. On completion of data collection at one year follow-up, comparison schools received a copy of the SFS training manual, and children were given a SFS water bottle, drawstring bag and pen for participating in the research study.

\section{Measures}

The primary outcome measure was intentions (not) to smoke of the participating children; secondary outcomes included individual smoking-related cognitions (attitudes and refusal self-efficacy). Outcomes were assessed based on a self-reported questionnaire completed by children at T0, T1 and T2, and through focus groups with children, which were conducted at $\mathrm{T} 1$ only due to funding restrictions.

\section{Smoking questionnaire}

A questionnaire was constructed using items adapted from questionnaires previously used with this age group [54-57]. Background demographic information has been described in detail elsewhere [14]. Briefly, demographics assessed included age (years), gender $(1=$ girl, $0=$ boy), ethnicity ( $1=$ white British, $0=$ other) and SES (home postcodes were used to generate indices of multiple deprivation (IMD) scores [39]. Children's enjoyment of physical activity was assessed using the 16 item Physical Activity Enjoyment Scale [58]. Parent, sibling and friend smoking behaviour ( $1=$ smokes (parent/sibling/friend) or tried (friend only), $0=$ non-smoker) was assessed using an item from the Health Survey for England [57]. Child smoking behaviour $(0=$ never smoked, $1=$ ever smoked) was also measured for descriptive purposes using a single item from the Health Survey for England [57]. As an indicator of smoking status, expired carbon monoxide $(\mathrm{CO})$ concentrations were taken in private and recorded using a piCOsimple Smokerlyzer (Bedfont Scientific UK, England) with a reading above 10 ppm used as cut-off for defining smokers [59].

Intention (not) to smoke was assessed using two items from the Health Survey for England [57], 'Do you think you will smoke in the next month/year?', as well as an item designed by the research team 'Do you think you will smoke in secondary school?'. Responses ranged from 'definitely yes' (1) to 'definitely not' (4) and were summed to produce a total intention score (range 312). A high score on total intention indicated a strong 
intention not to smoke. Cronbach alpha for total intention showed good internal consistency $(\alpha=0.81)$.

Refusal self-efficacy was measured using three items adapted from a nine-item self-efficacy scale in adolescents [54]. Items assessed the child's confidence in their ability to be a non-smoker and refuse cigarettes in different situations. Responses consisted of Likert scales ranging from 'not confident at all' (1) to 'very confident' (5) and were summed to create a total refusal self-efficacy score (range 3-15). Cronbach alpha for the combined scale showed good internal consistency $(\alpha=0.81)$. A high score on the scale indicated a high level of refusal selfefficacy.

Attitude structure includes affective, behavioural and cognitive components [60]. For the purpose of this study, the cognitive component of children's attitudes was explored through items adapted from the Global Youth Tobacco Survey (GYTS) [56] and the Health Survey for England [57], including 'Do you think smoking is bad for your health?', 'Once someone has started smoking, do you think it will be difficult to quit?', 'Do you think that it is safe to smoke for only a year or two as long as you quit after that?', 'Do you think the smoke from other people's cigarettes is harmful to you?'. An additional item 'Do you think smoking effects sport performance?' was developed by the research team. Responses ranged from 'definitely not' (1) to 'definitely yes' (4). A summary scale was created but internal consistency was low $(\alpha=.49)$. Since the data for individual attitude items were positively skewed and distribution was not improved by statistical transformation, responses were collapsed into dichotomous variables for analyses: a definitive negative attitude towards smoking (i.e. 'definitely yes') was scored 1 ; the remaining response categories (i.e. 'probably yes', 'probably not' and 'definitely not') indicated a more favourable attitude towards smoking and thus were collapsed into a single group and scored 0 . One attitude item ('Do you think that it is safe to smoke for only a year or two as long as you quit after that?') was reverse coded in order to maintain consistent scale direction for all items. An additional attitude item, 'Do you think smoking makes you gain weight?' was also included from the Health Survey for England [57]. Whilst it is recognised that smoking is associated with weight loss [61], smoking is widely discouraged by public health professionals for weight control. Therefore, a key message included within the curriculum was that regular physical activity and healthy eating, but not smoking, was important for maintenance of a healthy weight. Thus responses for this item were collapsed into a dichotomous variable for analysis with 'no difference' scored 1 and the remaining response categories (i.e., 'lose weight' or 'gain weight') grouped and scored 0 .

\section{Focus groups with children}

Eighteen mixed-sex focus groups with children $(n=95$; $45 \%$ boys) were facilitated by trained researchers immediately following the intervention [T1]. Focus groups comprised of five to six children, lasted between 30 and $50 \mathrm{~min}$ and were audio recorded using a Dictaphone. Children's perceptions of smoking, appropriateness of the intervention, and improvements for future implementation were explored. Photographs of SFS games were used to help children recall activity type $[62,63]$. To aid the credibility of data, facilitators' reflected interpretations back to children during the focus groups. The present study focuses on children's perceptions surrounding the impact of SFS on intentions (not) to smoke and individual smoking-related cognitions, thus other findings are discussed in the process evaluation paper, which has been published elsewhere [64].

\section{Analyses}

Participants with missing data at either post-intervention [T1] or follow-up [T2] were not considered in the analyses (i.e., a complete case analysis). To describe the demographic characteristics of children at baseline [T0] and differences concerning primary (smoking intentions) and secondary outcomes (attitudes towards smoking and refusal self-efficacy), general descriptive analyses were conducted. Independent t-tests and chi-square tests were used to assess whether the primary and secondary outcomes differed between the study groups at baseline, and to assess differences between those participants included and excluded from the final analysis. Multilevel linear and logistic regression analyses examined intervention effects on the primary and secondary outcomes. To account for the clustering effect among children being nested in schools, a two-level data structure was conducted. Children were defined as the first level unit of analysis and schools the second level unit of analysis [65]. Two analyses were conducted for each of the outcome variables to examine the intervention effects. The first analysis determined the difference between the intervention and comparison group adjusting for baseline value of the outcome measure ('crude' analysis). The second analysis determined this effect when the covariates were added to the model ('adjusted' analysis); these covariates included age, ethnicity, deprivation level, mother/father/sibling/friend smoking, intentions to smoke and individual smokingrelated cognitions, since these variables may influence each other $[9,51]$. Additionally, physical activity enjoyment was adjusted for in the analysis because we hypothesised that children who enjoy physical activity may be more amenable to a sport-for-health intervention. In addition, separate analyses for boys and girls were performed to assess intervention effects between baseline and post-intervention, and baseline and one 
year follow-up. To determine whether the intervention effect was different for boys and girls, a dichotomous interaction term (labelled 'sex') was constructed. Regression coefficients in each model were assessed for significance using the Wald statistic with one degree of freedom. As the prevalence of negative attitudes towards smoking was high in both study arms, odds ratios were converted to relative risks [66] to avoid overestimation of effects and for ease of interpretation of results. Analyses were performed using IBM SPSS Statistics v.22 and MLwiN 2.30 software (Centre for Multi-level Modelling, University of Bristol, UK). Statistical significance was set at $p<0.05$, and at $p<0.10$ for the sex interaction term [66].

Child focus groups were transcribed verbatim, imported into NVivo 10 software, and subjected to thematic analysis [67]. This process involved reading and re-reading text and assigning broad thematic codes, some of which were pre-defined from topics covered in the group schedule. Subsequently, broad codes were collapsed into higher and lower order themes and descriptive and interpretive summaries were written based on recursive engagement with the data. A combination of inductive analysis and deductive techniques were used to generate codes. To aid the credibility and trustworthiness of the results, analyses and interpretations of the data were discussed amongst three members (CM, JT and LF) of the research team [67].

\section{Results}

Figure 2 shows the flow of schools and participants through the trial. In total, 43 schools participated in the study (27.9 \% response rate), including 32 (31 \%) from Liverpool and 11 (22\%) from Knowsley. Schools that declined to participate provided diverse reasons for not taking part (e.g., too busy, key teacher on sick leave, already in

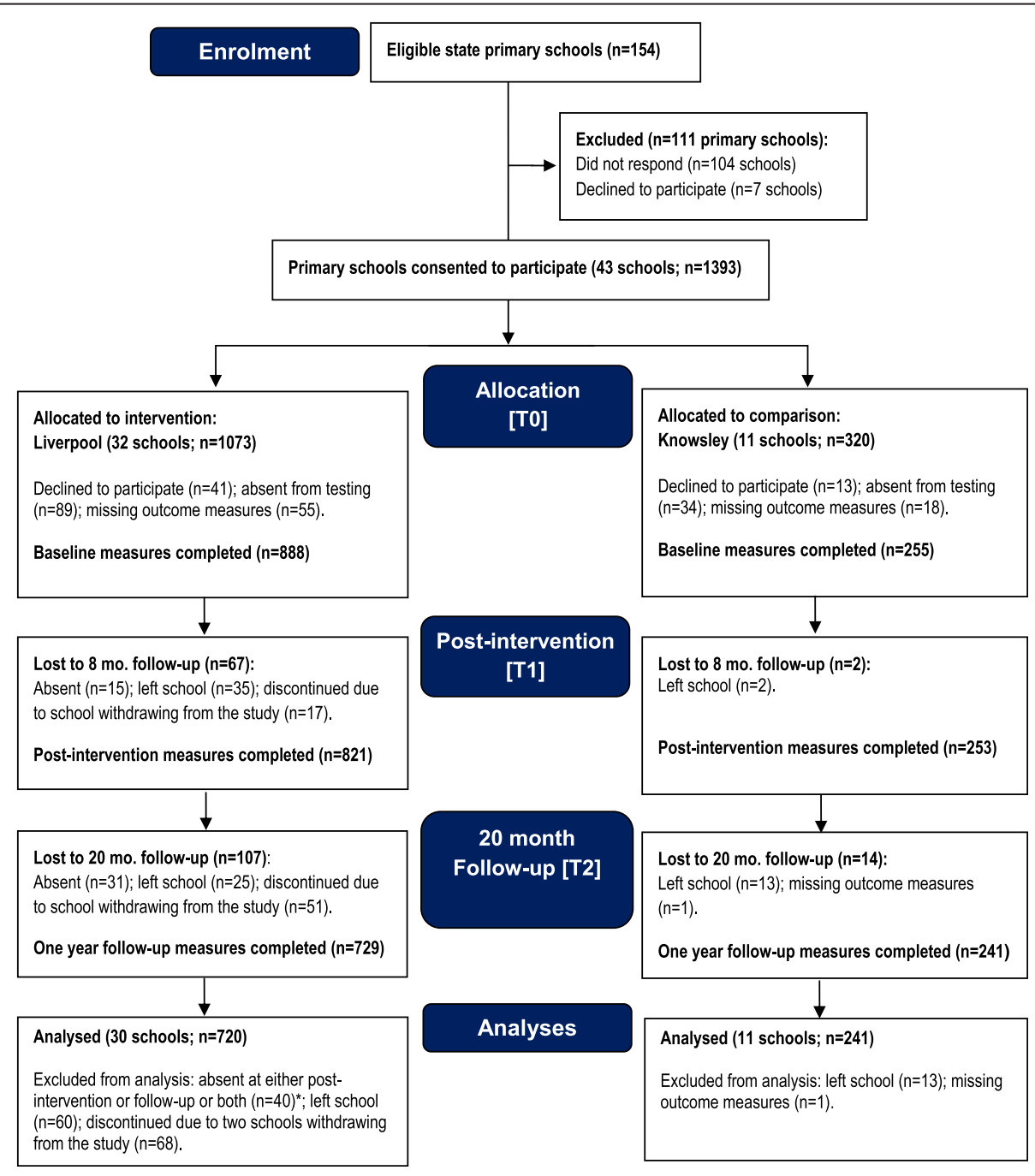

Fig. 2 Flow of schools and participants through the study. *Six children were absent at both post-intervention and follow-up 
receipt of external projects). Of the 1393 potentially eligible children at T0, 1143 completed baseline measures (92\% response rate); 961 children completed assessments at $\mathrm{T} 0$, $\mathrm{T} 1$, and $\mathrm{T} 2$ and were included in the final analyses $(84 \%$ participation rate). Participant retention ranged from $80 \%$ (T0) to $79 \%$ (T2) in the comparison group. The intervention group's retention ranged from $83 \%$ at baseline to $68 \%$ at T2. However, the withdrawal of two intervention schools due to internal staffing issues excluded 68 children. Had the schools not withdrawn, assuming all children would have continued through the study, the retention at follow-up would have been $74 \%$. Compared with intervention children included in the analyses, a higher proportion of intervention children that were excluded from the analyses had a sibling that smoked $(p<0.01)$ and a lower proportion believed that smoking is bad for health $(p<0.05)$. Other baseline values did not differ between those included and excluded.

Baseline characteristics for the final sample of child participants (mean age $9.6 \pm 0.3$ years, $50.4 \%$ female, $98.3 \%$ White British) are shown in Table 1. Over seven in ten $(71.9 \%)$ participating children lived within areas ranked within the highest $10 \%$ for deprivation in England. The majority of children reported to have never smoked at T0 (97.5\%: comparison group, $96.3 \%$; intervention group, $97.9 \%)$. CO readings were recorded for $82 \%$ of participants and confirmed self-reported non-smoking status with all readings below $10 \mathrm{ppm}$ (Mean $=1.3 \pm$ $0.7 \mathrm{ppm}$ ). Over half of children (57.3\%) reported that at least one family member was a current smoker, whilst almost one in five children reported having a friend who smoked. Children generally had strong non-smoking intentions and high refusal self-efficacy expectations, though 40-58 \% of children displayed more favourable attitudes towards smoking on five of the six attitude items. Children in the intervention group were less likely to be White British and were significantly more deprived $(p<0.01)$ than children in the comparison group. A higher proportion of intervention children, in particular girls, definitely believed that smoking was difficult to quit $(p<0.01)$ and that smoking affects sports performance $(p<0.05)$. No other significant group differences were found at $\mathrm{T} 0$.

Smoking behaviour data is reported for descriptive purposes. Self-reported smoking prevalence at T1

Table 1 Sample characteristics of children at baseline

\begin{tabular}{|c|c|c|c|c|c|c|}
\hline & \multicolumn{3}{|l|}{ Comparison } & \multicolumn{3}{|l|}{ Intervention } \\
\hline & $\begin{array}{l}\text { All }(n=241) \\
M \pm S D \text { or } \%\end{array}$ & $\begin{array}{l}\text { Boys }(n=114) \\
M \pm S D \text { or } \%\end{array}$ & $\begin{array}{l}\text { Girls }(n=127) \\
M \pm S D \text { or } \%\end{array}$ & $\begin{array}{l}\text { All }(n=720) \\
M \pm S D \text { or } \%\end{array}$ & $\begin{array}{l}\text { Boys }(n=363) \\
M \pm S D \text { or } \%\end{array}$ & $\begin{array}{l}\text { Girls }(n=357) \\
\mathrm{M} \pm \mathrm{SD} \text { or } \%\end{array}$ \\
\hline \multicolumn{7}{|l|}{ Demographics } \\
\hline Age (years) & $9.6 \pm 0.3$ & $9.6 \pm 0.3$ & $9.6 \pm 0.3$ & $9.6 \pm 0.3$ & $9.6 \pm 0.3$ & $9.6 \pm 0.3$ \\
\hline Ethnicity (White British) & 98.3 & 99.1 & 97.6 & 82.1 & 82.6 & 81.5 \\
\hline Deprivation level (IMD) & $50.9 \pm 17.9$ & $49.8 \pm 17.7$ & $51.9 \pm 18.2$ & $55.7 \pm 16.4$ & $55.5 \pm 16.5$ & $55.8 \pm 16.3$ \\
\hline \multicolumn{7}{|l|}{ Enjoyment of physical activity } \\
\hline PACES enjoyment scale (range 1-5) & $4.3 \pm 0.7$ & $4.3 \pm 0.7$ & $4.3 \pm 0.7$ & $4.3 \pm 0.7$ & $4.2 \pm 0.8$ & $4.4 \pm 0.6$ \\
\hline \multicolumn{7}{|l|}{ Smoking intentions } \\
\hline Total non-smoking intentions (range 4-12) & $11.7 \pm 1.0$ & $11.6 \pm 1.1$ & $11.7 \pm 0.9$ & $11.8 \pm 0.8$ & $11.7 \pm 1.0$ & $11.9 \pm 0.5$ \\
\hline \multicolumn{7}{|l|}{ Self-efficacy } \\
\hline Total refusal self-efficacy (range 3-15) & $13.5 \pm 3.2$ & $13.5 \pm 3.1$ & $13.5 \pm 3.3$ & $13.7 \pm 3.0$ & $13.4 \pm 3.3$ & $14.0 \pm 2.7$ \\
\hline \multicolumn{7}{|l|}{ Attitudes towards smoking } \\
\hline Smoking is bad for health ('definitely yes') & 88.8 & 87.7 & 89.8 & 90.1 & 86.2 & 94.1 \\
\hline Safe to smoke year or two ('definitely not') & 59.8 & 60.5 & 59.1 & 64.4 & 63.6 & 65.3 \\
\hline Difficult to quit once started ('definitely yes') & 43.2 & 45.6 & 40.9 & 52.8 & 51.2 & 54.3 \\
\hline Others smoke harmful to you ('definitely yes') & 59.3 & 60.5 & 58.3 & 66.1 & 63.1 & 69.2 \\
\hline Affects sports performance ('definitely yes') & 51.0 & 53.5 & 48.8 & 58.3 & 59.2 & 57.4 \\
\hline Makes you gain/lose weight ('no difference') & 42.3 & 37.7 & 46.5 & 42.6 & 45.2 & 40.1 \\
\hline \multicolumn{7}{|l|}{ Social influences } \\
\hline Mother smoking & 40.7 & 39.5 & 41.7 & 34.9 & 32.2 & 37.5 \\
\hline Father smoking & 43.6 & 47.4 & 40.2 & 38.2 & 38.0 & 38.4 \\
\hline Sibling smoking & 10.8 & 10.5 & 11.0 & 9.2 & 8.0 & 10.4 \\
\hline Friend smoking ${ }^{a}$ & 18.7 & 25.4 & 12.6 & 17.1 & 22.9 & 11.2 \\
\hline
\end{tabular}

Notes: IMD, Indices of multiple deprivation score; ${ }^{\text {at }}$ least one friend smokes or tried 
(comparison group, $97.5 \%$; intervention group, $98.6 \%$ ) and T2 (comparison group: $97.1 \%$, intervention group, $98.2 \%$ ) remained similar to $\mathrm{T} 0$, suggesting that low rates of smoking continued over time.

\section{Intervention effects}

\section{Non-smoking intentions}

The adjusted multilevel linear regression analyses indicated no significant intervention effects on non-smoking intentions between baseline and T1 (Table 2), and between baseline and T2 (Table 3).

\section{Cigarette refusal self-efficacy}

The adjusted multilevel linear regression analyses showed no significant intervention effects between baseline and T1 (Table 2), and between baseline and T2 (Table 3), for refusal self-efficacy.

\section{Attitudes towards smoking}

The adjusted multilevel logistic regression analyses indicated small positive intervention effects between baseline and T1 (Table 2) for four attitude towards smoking items. At $\mathrm{T} 1$, compared with children in the comparison group, children that participated in the SFS intervention were more likely to 'definitely' believe that: 'it is not safe to smoke for a year or two as long as you quit after that' ( $\mathrm{RR}=1.19,95 \% \mathrm{CI} 1.07$ to $1.33, p<0.001)$, 'it is difficult to quit smoking once started' $(\mathrm{RR}=1.56,95 \% 1.38$ to $1.76, p<0.001$ ), 'smoke from other peoples' cigarettes is harmful to you' ( $R R=1.19,95 \%$ CI 1.20 to $2.08, p<0.001)$, and 'smoking affects sports performance' ( $R R=1.73,95 \%$ CI 1.59 to $1.88, p<0.001)$. In addition, a moderate positive intervention effect was observed on the attitude item: 'smoking makes 'no difference' to weight' $(\mathrm{RR}=2.13$, $95 \%$ CI 1.86 to $2.44, p<0.001)$. Between baseline and T2 (Table 3), significant between-group differences remained on only one of the six attitude items. Compared with children in the comparison group, children who received the SFS intervention were more likely to 'definitely' believe that 'smoking affects sports performance' $(\mathrm{RR}=1.57,95 \% \mathrm{CI}, 1.43,1.72, p<0.001)$, a small positive intervention effect.

Table 2 Multilevel analyses of the effectiveness of the SmokeFree Sports intervention between baseline (T0) and post-intervention (T1)

\begin{tabular}{|c|c|c|c|c|c|c|}
\hline \multirow[b]{2}{*}{ Outcome measure } & \multirow{2}{*}{\multicolumn{2}{|c|}{$\begin{array}{l}\text { Mean difference }{ }^{a} \\
\text { (T1-T0: } M \pm S D \text { or \%) }\end{array}$}} & \multicolumn{2}{|l|}{ Crude model $^{\mathrm{b}}$} & \multicolumn{2}{|l|}{ Adjusted model $^{c}$} \\
\hline & & & $\beta$ or $\mathrm{RR}(95 \% \mathrm{Cl})$ & $P$ & $\beta$ or $\mathrm{RR}(95 \% \mathrm{Cl})$ & $P$ \\
\hline \multicolumn{7}{|l|}{ Smoking intentions } \\
\hline \multirow[t]{2}{*}{ Total non-smoking intentions } & 1 & $0.03 \pm 0.98$ & $0.03^{\mathrm{d}}(-0.07,0.13)$ & 0.51 & $0.02^{d}(-0.08,0.12)$ & 0.71 \\
\hline & C & $0.07 \pm 0.95$ & & & & \\
\hline \multicolumn{7}{|l|}{ Cigarette refusal self-efficacy } \\
\hline \multirow[t]{2}{*}{ Total refusal self-efficacy } & । & $0.29 \pm 3.52$ & $0.28^{\mathrm{d}}(-0.10,0.67)$ & 0.15 & $0.28^{d}(-0.11,0.67)$ & 0.17 \\
\hline & C & $0.15 \pm 3.77$ & & & & \\
\hline \multicolumn{7}{|l|}{ Attitudes towards smoking } \\
\hline \multirow[t]{2}{*}{ Smoking is bad for health ('definitely yes') } & 1 & 3.8 & $1.03^{\mathrm{e}}(0.99,1.06)$ & 0.19 & $1.03^{\mathrm{e}}(0.99,1.06)$ & 0.15 \\
\hline & C & 2.5 & & & & \\
\hline \multirow[t]{2}{*}{ Safe to smoke...year or two ('definitely not') } & 1 & 3.1 & $1.23^{\mathrm{e}}(1.11,1.36)$ & $<0.001^{*}$ & $1.19^{\mathrm{e}}(1.07,1.33)$ & 0.01 \\
\hline & C & -5.0 & & & & \\
\hline \multirow[t]{2}{*}{ Difficult to quit once started ('definitely yes') } & 1 & 15.4 & $1.58^{\mathrm{e}}(1.41,1.78)$ & $<0.001^{*}$ & $1.56^{\mathrm{e}}(1.38,1.76)$ & $<0.001^{*}$ \\
\hline & C & -0.5 & & & & \\
\hline \multirow[t]{2}{*}{ Others smoke is harmful to you ('definitely yes') } & 1 & 2.4 & $1.19^{\mathrm{e}}(1.07,1.31)$ & $<0.01^{*}$ & $1.19^{\mathrm{e}}(1.20,2.08)$ & $<0.01^{*}$ \\
\hline & C & -2.5 & & & & \\
\hline \multirow[t]{2}{*}{ Affects sports performance ('definitely yes') } & 1 & 30.3 & $1.70^{\mathrm{e}}(1.58,1.85)$ & $<0.001^{*}$ & $1.73^{\mathrm{e}}(1.59,1.88)$ & $<0.001^{*}$ \\
\hline & C & 0.9 & & & & \\
\hline \multirow[t]{2}{*}{ Makes you gain or lose weight ('no difference) } & 1 & 26.3 & $2.11^{\mathrm{e}}(1.85,2.41)$ & $<0.001^{*}$ & $2.13^{\mathrm{e}}(1.86,2.44)$ & $<0.001^{*}$ \\
\hline & C & -9.1 & & & & \\
\hline
\end{tabular}

Notes: $\beta=$ beta coefficient; $\mathrm{RR}=$ relative risk; $\mathrm{Cl}=$ confidence interval, $\mathrm{I}=$ intervention group; $\mathrm{C}=$ comparison. Values reflect the intervention effects (i.e., between-group differences) between baseline and post-intervention

* Significant intervention effect $(P<0.05)$

annadjusted within-group mean difference (post-intervention minus baseline)

${ }^{b}$ Adjusted for group and baseline value of the outcome measure

'Additionally adjusted for school and deprivation level, sex, age, ethnicity, other individual smoking-related cognitions at baseline, enjoyment of physical activity and mother/father/sibling/friend smoking

d $\beta$ value

${ }^{\mathrm{e}}$ Relative risk 
Table 3 Multilevel analyses of the effectiveness of the SmokeFree Sports intervention between baseline (T0) and one year follow-up (T2)

\begin{tabular}{|c|c|c|c|c|c|c|}
\hline \multirow[b]{2}{*}{ Outcome measure } & \multirow{2}{*}{\multicolumn{2}{|c|}{$\begin{array}{l}\text { Mean difference } \\
\text { (T2-T0: } \mathrm{M} \pm \mathrm{SD} \text { or } \%)\end{array}$}} & \multicolumn{2}{|l|}{ Crude model $^{b}$} & \multicolumn{2}{|l|}{ 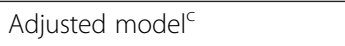 } \\
\hline & & & $\beta$ or $\mathrm{RR}(95 \% \mathrm{Cl})$ & $\mathrm{P}$ & $\beta$ or $\mathrm{RR}(95 \% \mathrm{Cl})$ & $\mathrm{P}$ \\
\hline \multicolumn{7}{|l|}{ Smoking intentions } \\
\hline \multirow[t]{2}{*}{ Total non-smoking intentions } & । & $0.06 \pm 0.97$ & $0.08^{\mathrm{d}}(-0.02,0.18)$ & 0.13 & $0.08^{d}(-0.02,0.17)$ & 0.14 \\
\hline & $\mathrm{C}$ & $0.06 \pm 1.18$ & & & & \\
\hline \multicolumn{7}{|l|}{ Cigarette refusal self-efficacy } \\
\hline \multirow[t]{2}{*}{ Total refusal self-efficacy } & । & $0.56 \pm 3.23$ & $0.27^{d}(-0.02,0.56)$ & 0.07 & $0.23^{d}(-0.07,0.52)$ & 0.13 \\
\hline & C & $0.45 \pm 3.73$ & & & & \\
\hline \multicolumn{7}{|l|}{ Attitudes towards smoking } \\
\hline \multirow[t]{2}{*}{ Smoking is bad for health ('definitely yes) } & । & 5.5 & $0.98^{\mathrm{e}}(0.96,1.01)$ & 0.28 & $0.99^{\mathrm{e}}(0.97,1.01)$ & 0.42 \\
\hline & C & 8.3 & & & & \\
\hline \multirow[t]{2}{*}{ Safe to smoke...year or two ('definitely not') } & I & -0.6 & $1.05^{\mathrm{e}}(0.95,1.16)$ & 0.42 & $1.03^{\mathrm{e}}(0.93,1.15)$ & 0.65 \\
\hline & C & 0.4 & & & & \\
\hline \multirow[t]{2}{*}{ Difficult to quit once started ('definitely yes') } & । & 5.8 & $1.15^{\mathrm{e}}(1.02,1.29)$ & 0.05 & $1.15^{\mathrm{e}}(1.02,1.3)$ & 0.06 \\
\hline & C & 6.6 & & & & \\
\hline \multirow[t]{2}{*}{ Others smoke is harmful to you ('definitely yes') } & । & 0.0 & $1.14^{\mathrm{e}}(1.08,1.81)$ & 0.03 & $1.13^{\mathrm{e}}(1.05,1.79)$ & 0.05 \\
\hline & $\mathrm{C}$ & -2.0 & & & & \\
\hline \multirow[t]{2}{*}{ Affects sports performance ('definitely yes') } & । & 23.2 & $1.55^{\mathrm{e}}(1.42,1.69)$ & $<0.001^{*}$ & $1.57^{\mathrm{e}}(1.43,1.72)$ & $<0.001^{*}$ \\
\hline & $\mathrm{C}$ & 1.3 & & & & \\
\hline \multirow[t]{2}{*}{ Makes you gain or lose weight ('no difference) } & । & -2.0 & $1.05^{\mathrm{e}}(0.90,1.22)$ & 0.60 & $0.98^{\mathrm{e}}(0.83,1.16)$ & 0.84 \\
\hline & C & -3.7 & & & & \\
\hline
\end{tabular}

Notes: $\beta=$ beta coefficient; $\mathrm{RR}=$ relative risk; $\mathrm{Cl}=$ confidence interval; $\mathrm{I}=$ intervention group; $\mathrm{C}=$ comparison. Values reflect the intervention effects (i.e., between-group differences) between baseline and post-intervention *Significant intervention effect $(P<0.05)$

a Unadjusted within-group mean difference (one year follow-up minus baseline)

${ }^{\mathrm{b}}$ Adjusted for group and baseline value of the outcome measure

'Additionally adjusted for school and deprivation level, sex, age, ethnicity, other individual smoking-related cognitions at baseline, enjoyment of physical activity and mother/father/sibling/friend smoking

${ }^{\mathrm{d}} \beta$ value

Relative risk

\section{Sex interaction effects}

Tables 4 and 5 show the results of the sex interaction analyses between baseline and $\mathrm{T} 1$, and between baseline and $\mathrm{T} 2$, respectively. Between baseline and $\mathrm{T} 1$, sex moderated the intervention effects for cigarette refusal self-efficacy; a significant small positive intervention effect was found in girls $(\beta=0.72,95 \% \mathrm{CI}$ 0.21 to $1.23, p<0.01)$ but not boys $(\beta=-0.18,95 \% \mathrm{CI}$ -0.77 to $0.41, p=0.54)$. No other sex interactions were observed.

\section{Qualitative findings}

During focus groups the majority of children articulated that SFS made them more determined not to smoke in the future. Children's reasons for not smoking surrounded some of the key messages received and or activities played during the intervention (see Table 6 for a summary of children's reasons for their non-smoking intentions). During group discussions some children expressed a level of uncertainty regarding their future smoking behaviour and verbalised that they may smoke in the future because of social norms, and or using smoking as a coping mechanism for managing stress:

"I don't want to smoke when I'm older but I'll probably end up changing my mind because I want to be like one of my sisters who smokes" (Girl, School 1).

"I'm not saying I definitely won't [smoke] because it's just something that might happen if something stressful happens" (Boy, School 2).

During group discussions children were able to recall the health messages delivered during the intervention, particularly in relation to the health implications associated with smoking, its impact on sport performance, the chemical properties in a cigarette and its addictive nature, and its impact on weight (see Table 7).

\section{Discussion}

This study examined the short and medium term effects of a sport-for-health intervention (SFS) on 9-10 year old 
Table 4 Multilevel analyses exploring interaction effects by sex between baseline (T0) and post-intervention (T1)

\begin{tabular}{|c|c|c|c|c|c|c|c|c|c|}
\hline \multirow{2}{*}{ Outcome measure } & & \multicolumn{2}{|c|}{$\begin{array}{l}\text { Mean difference }{ }^{a} \\
\text { (T1-T0: } \mathrm{M} \pm \text { SD or \%) }\end{array}$} & \multicolumn{2}{|l|}{$\begin{array}{l}\text { Intervention* } \text { sex }^{\mathrm{b}} \\
\text { (crude model) }\end{array}$} & \multirow{2}{*}{$\begin{array}{l}\text { Boys }^{c} \\
\beta \text { or RR }(95 \% \mathrm{Cl})\end{array}$} & \multirow[b]{2}{*}{$\mathrm{P}$} & \multicolumn{2}{|l|}{ Girls $s^{c}$} \\
\hline & & Boys & Girls & $\beta$ or RR $(95 \% \mathrm{Cl})$ & $P$ & & & $\beta$ or $\operatorname{RR}(95 \% \mathrm{Cl})$ & $P$ \\
\hline \multicolumn{10}{|l|}{ Smoking intentions } \\
\hline \multirow[t]{2}{*}{ Total non-smoking intentions } & 1 & $0.10 \pm 1.2$ & $-0.04 \pm 0.7$ & $0.10^{d}(-0.10,0.30)$ & 0.32 & $\mathrm{n} / \mathrm{a}$ & - & $\mathrm{n} / \mathrm{a}$ & - \\
\hline & C & $0.16 \pm 1.0$ & $0.00 \pm 0.9$ & & & & & & \\
\hline \multicolumn{10}{|l|}{ Cigarette refusal self-efficacy } \\
\hline \multirow[t]{2}{*}{ Total refusal self-efficacy } & I & $0.32 \pm 3.9$ & $0.25 \pm 3.2$ & $0.87^{d}(0.09,1.64)$ & $0.03^{*}$ & $-0.18^{d}(-0.77,0.41)$ & 0.54 & $0.72^{d}(0.21,1.23)$ & $<0.01^{*}$ \\
\hline & C & $0.39 \pm 3.6$ & $-0.07 \pm 3.8$ & & & & & & \\
\hline \multicolumn{10}{|l|}{ Attitudes towards smoking } \\
\hline \multirow{2}{*}{$\begin{array}{l}\text { Smoking is bad for health } \\
\text { ('definitely yes') }\end{array}$} & 1 & 5.5 & 2.0 & $1.05^{\mathrm{e}}(1.00,1.11)$ & 0.12 & $\mathrm{n} / \mathrm{a}$ & - & $\mathrm{n} / \mathrm{a}$ & - \\
\hline & C & 4.4 & 0.8 & & & & & & \\
\hline \multirow{2}{*}{$\begin{array}{l}\text { Safe to smoke... year or two } \\
\text { ('definitely not') }\end{array}$} & 1 & 0.9 & 5.3 & $1.16^{\mathrm{e}}(0.95,1.42)$ & 0.23 & $\mathrm{n} / \mathrm{a}$ & - & n/a & - \\
\hline & C & -4.4 & -5.6 & & & & & & \\
\hline \multirow{2}{*}{$\begin{array}{l}\text { Difficult to quit once started } \\
\text { ('definitely yes') }\end{array}$} & I & 17.4 & 13.5 & $1.19^{\mathrm{e}}(0.90,1.57)$ & 0.30 & $\mathrm{n} / \mathrm{a}$ & - & $\mathrm{n} / \mathrm{a}$ & - \\
\hline & C & 2.6 & -3.1 & & & & & & \\
\hline \multirow{2}{*}{$\begin{array}{l}\text { Others smoke harmful to you } \\
\text { ('definitely yes') }\end{array}$} & 1 & 3.3 & 1.4 & $1.14^{\mathrm{e}}(0.84,2.23)$ & 0.29 & $\mathrm{n} / \mathrm{a}$ & - & $\mathrm{n} / \mathrm{a}$ & - \\
\hline & C & -0.9 & -4.0 & & & & & & \\
\hline \multirow{2}{*}{$\begin{array}{l}\text { Affects sports performance } \\
\text { ('definitely yes') }\end{array}$} & 1 & 30.3 & 30.3 & $1.16^{\mathrm{e}}(0.90,1.50)$ & 0.34 & $\mathrm{n} / \mathrm{a}$ & - & $\mathrm{n} / \mathrm{a}$ & - \\
\hline & C & 5.3 & -3.1 & & & & & & \\
\hline \multirow{2}{*}{$\begin{array}{l}\text { Makes you gain or lose weight } \\
\text { ('no difference') }\end{array}$} & 1 & 23.4 & 29.1 & $1.21^{\mathrm{e}}(0.79,2.31)$ & 0.36 & $\mathrm{n} / \mathrm{a}$ & - & $\mathrm{n} / \mathrm{a}$ & - \\
\hline & C & -2.6 & -15.0 & & & & & & \\
\hline
\end{tabular}

Notes: $\beta$ = beta coefficient; $\mathrm{RR}=$ relative risk; $\mathrm{Cl}=$ confidence interval; $\mathrm{I}=$ intervention group; $\mathrm{C}=$ comparison. Where crude analyses were significant, adjusted analyses (i.e., interaction term included in adjusted multilevel models) were conducted with results for each sex shown

* Significant intervention effect $(P<0.05)$

${ }^{a}$ Unadjusted within-group mean difference (post-intervention minus baseline)

${ }^{\mathrm{b}}$ Adjusted for group and baseline value of the outcome measure

${ }^{c}$ Additionally adjusted for school and deprivation level, sex, age, ethnicity, other individual smoking-related cognitions at baseline, enjoyment of physical activity and mother/father/sibling/friend smoking

d $\beta$ value

Relative risk

children's intentions (not) to smoke and smokingrelated cognitions (attitudes and refusal self-efficacy) using a controlled trial. The SFS intervention had no effect on children's ratings of non-smoking intentions, though qualitative data suggested that participation in SFS made children more determined not to smoke. In addition, a small positive short term effect was found for refusal self-efficacy among girls in the intervention group. Participation in SFS also increased the likelihood of having negative attitudes towards smoking immediately after the intervention, with children stating that the intervention reinforced non-smoking opinions, though limited effects were found one year after the intervention.

Smoking intentions are precursors to and predictive of smoking initiation in youth $[8,68]$. Quantitative data indicated that the SFS intervention did not significantly impact on children's smoking intentions; children in both the intervention and comparison group reported a strong intention not to smoke in the future and thus a ceiling effect limited our ability to detect betweengroup differences. These findings are comparable to other smoking prevention programmes targeting primary school aged children $[19,69]$, but are inconsistent with two school-based interventions that reported a positive effect on intentions to smoke among elementary school children from the USA [70-72]. A further study examined the immediate and long term effects of a smoking education programme implemented in Dutch elementary schools [73]. The study reported no short term effects on intention to smoke during elementary school. However, when children were followed up at secondary school 
Table 5 Multilevel analyses exploring interaction effects by sex between baseline (T0) and one year follow-up (T2)

\begin{tabular}{|c|c|c|c|c|c|c|c|c|c|}
\hline \multirow[b]{2}{*}{ Outcome measure } & & \multicolumn{2}{|c|}{$\begin{array}{l}\text { Mean difference }{ }^{\mathrm{a}} \\
(\mathrm{T} 2-\mathrm{TO}: \mathrm{M} \pm \mathrm{SD} \text { or \%) }\end{array}$} & \multicolumn{2}{|l|}{$\begin{array}{l}\text { Intervention* sex } \\
\text { (crude model) }\end{array}$} & \multirow{2}{*}{$\begin{array}{l}\text { Boys }^{c} \\
\beta \text { or RR }(95 \% \mathrm{Cl})\end{array}$} & \multirow[b]{2}{*}{$\mathrm{P}$} & \multicolumn{2}{|l|}{ Girls $^{c}$} \\
\hline & & Boys & Girls & $\beta$ or $\operatorname{RR}(95 \% \mathrm{Cl})$ & $\mathrm{P}$ & & & $\beta$ or $\operatorname{RR}(95 \% \mathrm{Cl})$ & $\mathrm{P}$ \\
\hline \multicolumn{10}{|l|}{ Smoking intentions } \\
\hline \multirow[t]{2}{*}{ Total non-smoking intentions } & । & $0.10 \pm 1.2$ & $0.00 \pm 0.7$ & $-0.01^{\mathrm{d}}(-0.21,0.19)$ & 0.89 & $\mathrm{n} / \mathrm{a}$ & - & $\mathrm{n} / \mathrm{a}$ & - \\
\hline & C & $0.06 \pm 1.4$ & $0.06 \pm 0.9$ & & & & & & \\
\hline \multicolumn{10}{|l|}{ Cigarette refusal self-efficacy } \\
\hline \multirow[t]{2}{*}{ Total refusal self-efficacy } & । & $0.84 \pm 3.4$ & $0.27 \pm 3.0$ & $-0.20^{\mathrm{d}}(-0.78,0.39)$ & 0.51 & $n / a$ & - & $\mathrm{n} / \mathrm{a}$ & - \\
\hline & C & $0.37 \pm 3.8$ & $0.53 \pm 3.7$ & & & & & & \\
\hline \multicolumn{10}{|l|}{ Attitudes towards smoking } \\
\hline \multirow[t]{2}{*}{ Smoking is bad for health ('definitely yes') } & । & 8.3 & 2.5 & $1.02^{\mathrm{e}}(1.00,1.04)$ & 0.17 & $n / a$ & - & $\mathrm{n} / \mathrm{a}$ & - \\
\hline & C & 10.5 & 6.3 & & & & & & \\
\hline \multirow[t]{2}{*}{ Safe to smoke... year or two ('definitely not') } & । & -0.5 & -0.9 & $0.94^{\mathrm{e}}(0.76,1.17)$ & 0.64 & $\mathrm{n} / \mathrm{a}$ & - & $\mathrm{n} / \mathrm{a}$ & - \\
\hline & C & -2.6 & 3.1 & & & & & & \\
\hline \multirow[t]{2}{*}{ Difficult to quit once started ('definitely yes) } & । & 7.8 & 4.0 & $1.03^{\mathrm{e}}(0.81,1.31)$ & 0.84 & $n / a$ & - & $\mathrm{n} / \mathrm{a}$ & - \\
\hline & C & 6.2 & 7.1 & & & & & & \\
\hline \multirow[t]{2}{*}{ Others smoke harmful to you ('definitely yes') } & । & 1.6 & -1.7 & $1.11^{\mathrm{e}}(0.77,2.15)$ & 0.41 & $\mathrm{n} / \mathrm{a}$ & - & $\mathrm{n} / \mathrm{a}$ & - \\
\hline & C & -0.9 & -3.2 & & & & & & \\
\hline \multirow[t]{2}{*}{ Affects sports performance ('definitely yes') } & । & 25.1 & 21.3 & $1.05^{\mathrm{e}}(0.83,1.32)$ & 0.73 & $n / a$ & - & $\mathrm{n} / \mathrm{a}$ & - \\
\hline & C & 5.3 & -2.3 & & & & & & \\
\hline \multirow[t]{2}{*}{ Makes you gain or lose weight ('no difference) } & । & -2.5 & -1.7 & $0.99^{\mathrm{e}}(0.26,3.70)$ & 0.99 & $\mathrm{n} / \mathrm{a}$ & - & $\mathrm{n} / \mathrm{a}$ & - \\
\hline & C & 1.8 & -8.7 & & & & & & \\
\hline
\end{tabular}

Notes: $\beta$ = beta coefficient; $\mathrm{RR}=$ relative risk; $\mathrm{Cl}=$ confidence interval; I = intervention group; $\mathrm{C}=$ comparison. Where crude analyses were significant, adjusted analyses (i.e., interaction term included in adjusted multilevel models) were conducted with results for each sex shown

anadjusted within-group mean difference (one year follow-up minus baseline)

${ }^{\mathrm{b}}$ Adjusted for group and baseline value of the outcome measure

'Additionally adjusted for school and deprivation level, sex, age, ethnicity, other individual smoking-related cognitions at baseline, enjoyment of physical activity and mother/father/sibling/friend smoking

${ }^{\mathrm{d}} \beta$ value

Relative risk

Table 6 Children's reasons for their non-smoking intentions

\begin{tabular}{ll}
\hline Health messages & Quotes \\
\hline Health implications of smoking & "I won't [smoke] because if you smoke you will damage your heart and if you don't smoke you \\
can live a long and healthy life" (Girl, School 7). & "There's a reason why I wouldn't smoke because your lungs wouldn't be in the best condition" \\
& (Boy, School 10). \\
& "I wouldn't [smoke] because It's harder to breathe and harder to do exercise" (Boy, School 9). \\
& "Because I like doing lots of sports and if I smoked in the future it would be difficult to do \\
Isports]" (Boy, School 8). & "Because I've learnt [in SFS] how many chemicals are in a cigarette and what goes into them, \\
& that's why I wouldn't smoke" (Boy, School 8). \\
Cigarette contents and addiction & I'm very confident that I'm not going to smoke cos they've [SFS] told us how bad it [smoking] \\
is and there are over four thousand chemicals [in a cigarette] and it can be hard to quit" & (Girl, School 1). \\
"I wouldn't [smoke] because it costs you loads of money"(Girl, School 5).
\end{tabular}


Table 7 Children's' understanding of the health messages received during the intervention

\begin{tabular}{ll}
\hline Health messages & Quotes \\
\hline Health implications of smoking & "The [SFS] games show you the damage that [smoking] does to your arteries and lungs" (Boy, School 3). \\
& "A smoker would get more phlegm and a non-smoker would get less phlegm" (Boy, School 4, Gp 1). \\
Impact on sports performance & "Your heart beats faster when you're doing exercise when you're a smoker" (Boy, School 5). \\
Cigarette contents and addiction & "There's over 4,000 chemicals in a cigarette and they're not nice, rat poison, nicotine, rocket fuel" (Girl, School 6). \\
Impact on weight & "Peouldn't [smoke] because it's addictive and you won't be able to stop cos of the nicotine" (Girl, School 5). \\
& "It's healthier not to smoke and there's no difference in your weight, you're just better off not smoking"(Boy, School 6).
\end{tabular}

one year after the intervention, children who received the intervention had significantly higher non-smoking intentions and smoked less than the control group [73]. The above mentioned studies might suggest that smoking prevention interventions may be more effective if implemented in secondary school, as children may be more likely to have developed intentions to smoke if they are closer to the actual age of smoking onset (i.e., age 14-16 years [19, 73]. Nevertheless, given that qualitative data suggested that SFS had strengthened children's nonsmoking intentions, a longer term follow-up study is warranted to investigate whether implementing SFS during primary school is effective at reducing smoking behaviour and smoking intentions in adolescence, following the transition to secondary school.

Children's intentions to smoke can be shaped by their attitudes towards smoking and their self-efficacy expectations [9, 10, 74, 75]. Smoking-related knowledge and attitudes are frequently measured and have a propensity to increase following smoking prevention interventions [72, 76-78]. Consistent with these studies, children who participated in the SFS intervention were more likely to develop negative attitudes towards smoking immediately following the intervention than children in the comparison group. Focus group data with children supported these findings and revealed that the SFS games and smoke free messages positively influenced children. Given that many preadolescent children living in socially deprived communities display pro-smoking attitudes [14], these findings are encouraging and suggest that SFS could therefore provide a mechanism for health education to dispel myths that exist among children around smoking harms and challenges. However, it is also worth noting that the majority of the positive intervention effects on attitudes had diminished one year after the intervention. Though not directly comparable due to methodological differences, these results are in accord with Crone and colleagues [72], who also noted a number of short term positive between-group effects on attitudes towards smoking that had reduced by long term follow-up. It is possible, therefore, that additional 'booster' sessions may be necessary to sustain attitude changes in preadolescent children, particularly those residing in deprived communities. However, the evidence on the effectiveness of booster sessions is limited and inconsistent [79].

The likelihood of starting to smoke increases in adolescence $[80,81]$ and so enhancing skills to resist social pressures to smoke is important for smoking prevention [82]. Whilst a small positive effect was observed on cigarette refusal self-efficacy among girls in the intervention group at post-intervention, no group differences were apparent at one-year follow-up. It is possible that short term intervention effects on refusal self-efficacy were not found in boys because efficacy levels increased from baseline to post-intervention among boys in both the intervention and comparison groups. It is also possible that short term effects on girls' refusal self-efficacy were not maintained at one-year follow-up because girls' in the comparison groups ratings increased and they appeared to 'catch up'. These mixed findings likely reflect that self-efficacy is not a static concept [83] and levels of self-efficacy fluctuate over time [80]. The findings are similar to those reported by Isensee et al. [78], who also noted a lack of medium term effects and documented increases in refusal self-efficacy among control group participants. Further, the absence of intervention effect could again be attributed to a ceiling effect; children in the intervention and comparison groups both reported high refusal self-efficacy, reducing the power to detect noticeable effects. It is also worth noting that most children in the current study did not have friends who smoke, and so have yet to be put to the test of resisting social influences to smoke. Given that self-efficacy is subject to change over time, it has been recommended that smoking prevention programmes are implemented annually in preadolescence and throughout adolescence until the completion of secondary school [35, 77, 80]. Long-term research is required to determine if the SFS primary school smoking prevention intervention can 
facilitate children in making a rational and logical decision not to smoke during a period when smoking is more age-related and considered as accepted behaviour [84].

To the authors knowledge SFS was the first sport-forhealth intervention to engage children in smoking prevention. A recently published process evaluation of the intervention suggests that this unique approach was well-received by children, and was considered acceptable to coaches and teachers as intervention deliverers [64]. However, there were variations in intervention fidelity and teachers' implementation of intervention activities that may have reduced the potency of the intervention and the ability to sustain short term effects one year after the intervention [64]. Nevertheless, the limited intervention effects are more likely attributed to children at this age having strong intentions not smoke in the future, though important lessons have been learned that can inform the design of a randomised controlled trial [64].

The present study has several strengths. First, in accordance with MRC guidance for the development of complex interventions, SFS was designed following extensive formative work, school and community feasibility studies $[29,41,42]$. Second, this study adopted a mixedmethodology approach consistency with the Standard Evaluation Framework for physical activity interventions [85]. Third, this study followed children one year after the end of the intervention. Fourth, the study had a large sample size and reasonably low attrition rates were observed. Fifth, process evaluation measures were used to explore the implementation of SFS [64]. Finally, to the date, the results of this study provide the first globally published evidence for the effectiveness of a large scale school-based sport-for-health smoking prevention intervention.

Several limitations should be acknowledged. First, of the 154 schools approached, only 43 agreed to participate. Previous research has shown that some parents and school officials may be concerned that exposing preadolescent children to smoking prevention programmes may stimulate their interest and curiosity about smoking [86]. However, the primary reason given by schools for nonparticipation was limited time, which might be related to the fact that smoking prevention is not mandatory in Key Stage 2 of the UK National Curriculum [53]. Further, it was encouraging to note that participation in SFS did not increase rates of smoking initiation. Second, the reliance on self-report in the assessment of outcome variables carries a risk of measurement error due to inaccurate recall, literacy issues and social desirability bias [82, 87]. However, self-reports have been demonstrated to be accurate provided confidentially is assured [88]. Third, it was not possible to blind study participants or the research team to the intervention because of the practical nature of the intervention. Fourth, primary and secondary outcomes focused on intentions to smoke and smoking-related cognitions, respectively, which may or may not result in smoking initiation at a later age [13]. Fifth, given that the majority of children were White British and from one of the most deprived local authorities in England, these results may not generalise to other racial and socio-economic child populations. Sixth, focus groups were only conducted with children from intervention schools to inform interpretations of intervention effectiveness and therefore it is unknown if children from comparison schools would have conveyed similar perspectives. Finally, the study did not include a cost-effectiveness evaluation, thus it is unknown whether SFS is a costeffective smoking prevention initiative.

\section{Conclusions}

In summary, the results of this study indicate that SFS was effective at changing attitudes towards smoking, and increasing the level of individual self-efficacy to refuse cigarettes among girls immediately post-intervention. Although no quantitative intervention effects were observed for nonsmoking intentions, children articulated that SFS made them more determined not to smoke. Overall, these findings may suggest that sport-for-health interventions offer a promising strategy for smoking prevention efforts, though a long term follow-up study is needed to determine whether the SFS intervention is effective at preventing smoking in secondary school. Moreover, further evidence is needed from randomised controlled-trials. The fact that almost all children had not developed an intention to smoke might indicate that smoking prevention programmes should target early adolescents (aged 11-13 years), who are closer to the actual age of smoking onset.

\section{Acknowledgements \\ The funding for this project was provided by Liverpool City Council and Liverpool Primary Care Trust. The authors are grateful to all steering group members including; Helen Casstles (Liverpool Community Health NHS Trust); Claire Spencer (Liverpool City Council); Matthew Philpott (Health Equalities Group); Andrew Wileman (Merseyside Sports Partnership); Julie McCann (Healthy Schools); and Aaron Leach (Florence Melly Primary School) for their guidance and support in designing the SFS intervention. The authors would like to extend their thanks to Helen Casstles and Katie Dougherty (Liverpool Community Health NHS Trust) for co-delivering the bespoke training workshop and to the sports coaches from Liverpool City Council, Liverpool FC Foundation and Everton in the Community for delivering SFS activity sessions. Many thanks also go to the sports athletes Natasha Jonas (Boxing), Matthew Lee (Handball) and Tom Wolfenden (Badminton) for co-delivering the SFS assembly. Finally, we would like to thank all the primary schools and children who participated in this study.}

\section{Availability of data and materials}

The data from this study are not available in a public repository as participants were not informed that data would be archived or publicly shared. Researchers who wish to access the data for non-commercial purposes can make a request to the Principal Investigator, Dr Lawrence Foweather. 


\section{Authors' contributions}

CEM and LF drafted the manuscript and together with JT were responsible for data collection and analyses. LF conceived and managed the project as principal investigator. CM, JT, SF, RM, LP, MU and LF made substantial contributions to the study design, analysis, interpretation of data and editing the manuscript. All authors read and approved the final manuscript.

\section{Competing interests}

The authors declare that they have no competing interests.

\section{Author details}

${ }^{1}$ Centre for Public Health, Liverpool John Moores University, Henry Cotton Campus, 15-21 Webster Street, Liverpool L3 2AT, UK. ${ }^{2}$ Centre for Health Promotion Research, Leeds Beckett University, Calverley Building, City Campus, Leeds LS1 3HE, UK. ${ }^{3}$ Department of Sport and Physical Activity, Edge Hill University, St. Helens Road, Ormskirk, Lancashire L39 4QP, UK. ${ }^{4}$ Physical Activity Exchange, Research Institute for Sport and Exercise Sciences, Liverpool John Moores University, 62 Great Crosshall Street, Liverpool L3 2AT, UK. ${ }^{5}$ Population Health Research Institute, St George's, University of London, Cranmer Terrace, London SW17 ORE, UK. ${ }^{6}$ Department of Physical Education and Sport Sciences, University of Limerick, Limerick, Ireland.

\section{Received: 1 August 2015 Accepted: 20 April 2016}

\section{Published online: 26 May 2016}

\section{References}

1. Hopkinson NS, Lester-George A, Ormiston-Smith N, Cox A, Arnott D. Child uptake of smoking by area across the UK. Thorax. 2013. doi:10.1136/ thoraxinl-2013-204379.

2. Gervais A, O'Loughlin J, Meshefedjian G, Bancej C, Tremblay A. Milestones in the natural course of onset of cigarette use among adolescents. CMAJ. 2006;175(3):255

3. IARC. A review of human carcinogens. Personal habits and indoor combustions. IARC monographs on the evaluation of carcinogenic risks to humans 2012: Available at: http://monographs.iarc.fr/ENG/Monographs/ vol100E/mono100E.pdf. Accessed Sept 2013.

4. Funatogawa I, Funatogawa T, Yano E. Impacts of early smoking initiation: long-term trends of lung cancer mortality and smoking initiation from repeated cross-sectional surveys in Great Britain. BMJ Open. 2012. doi:10.1136/bmjopen-2012-001676.

5. Department of Health. Healthy lives, healthy people: A tobacco control plan for England. London: Department of Health 2011. Available at: https://www. gov.uk/government/uploads/system/uploads/attachment_data/file/213757/ dh_124960.pdf. Accessed Sep 2013.

6. Public Health England. E-cigarettes and harm reduction: where are we now and what next? 2014. Available at: https://publichealthmatters.blog.gov.uk/ 2014/05/21/e-cigarettes-and-harm-reduction-where-are-we-now-and-whatnext/. Accessed Sep 2013.

7. Health and Social Care Information Centre: Health Survey for England 2013: Health, social care and lifestyles. Available at: http://www.hscic.gov.uk/ catalogue/PUB16076. Accessed Jan 2014.

8. Andrews JA, Tildesley E, Hops H, Duncan SC, Severson HH. Elementary school age children's future intentions and use of substances. J Clin Child Adolesc Psychol. 2003;32:556-67.

9. Azjen, I. The theory of planned behaviour. Organizational Behavior and Human Decision Processes. 1991; 50:179-21.

10. Conrad KM, Flay BR, Hill D. Why children start smoking: predictors of onset. Br J Addict. 1998:87(12):1711-24.

11. de Vries H, Backbier E, Kok G, Dijkstra M. The impact of social influences in the context of attitude, self-efficacy, intention, and previous behavior as predictors of smoking onset. J Appl Soc Psycol. 1995;25(3):237-57.

12. Flay BR, Hu FB, Richardson J. Psychosocial predictors of different stages of cigarette smoking among high school students. Prev Med. 1998;275(5 Pt 3): A9-A18.

13. Cremers HP, Oenema L, Mercken L, Candel M, de Vries H. Explaining socioeconomic differences in intention to smoke among primary school children. BMC Public Health. 2014;14:191.

14. McGee CE, Trigwell J, Fairclough SJ, Murphy RC, Porcellato LA, Ussher M, Foweather $\mathrm{L}$. Influence of family and friend smoking on intentions to smoke and smoking-related attitudes and refusal self-efficacy among 9-10 year old primary school children from deprived neighbourhoods: a cross-sectional study. BMC Public Health. 2015;15:225.

15. Wen X, Chen W, Gans KM, Colby SM, Lu C, Liang C, Ling W. Two-year effect of a school-based prevention programme on adolescent cigarette smoking in Guangzhou, China: a cluster randomized trial. Int J Epidemiol. 2010;39(3):860-76.

16. Pommier J, Guevel MR, Jourdan D. Evaluation of health promotion in schools: a realistic evaluation approach using mixed methods. BMC Public Health. 2010;10:43.

17. Pearson M, Chiton R, Woods HB, Wyatt K, Ford T, Abraham C, Anderson R. Implementing health promotion in schools: protocol for a realist systematic review of research and experience in the United Kingdom (UK). Systematic Reviews. 2012. doi:10.1186/2046-4053-1-48.

18. Thomas RE, McLellan J, Perera R. Effectiveness of school-based smoking prevention curricula: systematic review and meta-analysis. BMJ. 2013;5: e06976. doi:10.1136/bmjopen-2014-006976.

19. Cremers HP, Mercken L, Candel M, de Vries H, Oenema A. A web-based, computer-tailored smoking prevention program to prevent children from starting to smoking after transferring to secondary school: randomized controlled trial. J Med Internet Res. 2015;17(3):1-12.

20. The Information Centre for Health and Social Care (2010). Smoking, drinking and drug use among young people in England in 2010. Available at: http://www.ic.nhs.uk/pubs/sdd10fullreport.

21. Simons-Morton B, Farhat T. Recent findings on peer group influences on adolescent substance use. J Prim Prev. 2010;31(4):191-208.

22. Vitoria PD, Salqueiro MF, Silva SA, de Vries H. Social influence, intention to smoke, and adolescent smoking behavior longitudinal relations. British J Health Psyc. 2011;16(4):779-98.

23. Smoking drinking and drug use among young people in England in (2014). Health \& Social Care Information Centre, 2015. Available at: http://www.hscic.gov. uk/catalogue/PUB17879/smok-drin-drug-youn-peop-eng-2014-rep.pdf.

24. Eime RM, Payne WR, Harvey JT. Making sports clubs healthy and welcoming environments: A strategy to increase participation. J Sci Med Sport. 2008;11:146-54

25. Priest N, Armstrong R, Doyle J, Waters E. Interventions implemented through sporting organisations for increasing participation in sport. Cochrane Database of Systematic Reviews, 2008; Issue 3. 1-15. doi:10.1002/ 14651858.CD004812.pub3.

26. Almond $L_{1}$ Almond $M$, Saunders $L$. Coaching sport for health: a review of the literature. Sports Coach UK. 2013; 1-9. Available from http://www. sportscoachuk.org/sites/default/files/ Coaching\%20Sport\%20for\%20Health\%20lit\%20review.pdf.

27. Geidne S, Qunnerstedt M, Erikson C. The youth sports club as a health promoting setting: An integrative review of research. Scand J Public Health. 2013;41:269.

28. Dubuy V, De Cocker K, De Bourdeaudhuij I, Maes L, Seghers J, Lefevre J, De Martelaer K, Brooke H, Cardon G. Evaluation of a real world intervention using professional football players to promote a healthy diet and physical activity in children and adolescents from a lower socio-economic background: a controlled pretest-posttest design. BMC Public Health. 2014;14:457-964.

29. Romeo-Velilla M, Beynon C, Murphy RC, McGee C, Hilland TA, Parnell D, Stratton G, Foweather, L. Formative evaluation of a UK community-based sports intervention to prevent smoking among children and young people: SmokeFree Sports. J Sport for Dev. 2013;2(3):1-10.

30. The US Centers for Disease Control and Prevention. Tobacco Free Sports Initiatives. Available at: http://www.cdc.gov/tobacco/youth/sports/playbook/ index.htm . Accessed Sep 2012.

31. Tobacco Free Athletes: a partnership for a tobacco-free Maine. Available at: http://www.tobaccofreemaine.org/channels/educators/tobacco_free_ athletes.php. Accessed Sep 2012.

32. Tobacco Free Sport and Recreation: Play Live Be Tobacco Free. Available at: www.playlivebetobaccofree.ca. Accessed Sep 2012.

33. Kacynski AT, Manske SR, Mannell RC, Grewal K. Smoking and physical activity: A systematic review. Am J Health Behav. 2008;32:93-110.

34. Horn K, Bransetter S, Zhang J, Jarret T, O'Hara-Tompkins N, Anesetti-Rothermel A, Olfert M, Richards T, Dino G. Understanding physical activity outcomes as a function of teen smoking cessation. J Adolesc Health. 2013;53:125-31.

35. National Institute for Clinical Excellence: School-based interventions to prevent smoking, 2010. Available at: https://www.nice.org.uk/guidance/ ph23. Accessed Sep 2012

36. Bailey R, Armour K, Kirk D, Jess M, Pickup I, Sandford R, et al. The educational benefits claimed for physical education and school sport: an academic review. Res Pap Educ. 2009;24(1):1-27. 
37. Donnelly J, Lambourne K. Classroom-based physical activity, cognition, and academic achievement. J Prevent Med. 2011;52:S36-42.

38. Kibbe DL, Hackett J, Hurley M, McFarland A, Godburn Schubert K, Schultz A, Harris S. Ten Years of TAKE 10! Integrating physical activity with academic concepts in elementary school classrooms. Prev Med. 2011. doi:10.1016/j. ypmed.2011.01.025.

39. Liverpool Public Health Intelligence Team. Key demographic and health statistics. Liverpool: Liverpool Primary Care Trust. London: Department for Communities and Local Government; 2010. Available at: https://www. gov.uk/government/statistics/english-indices-of-deprivation-2010. Accessed Sep 2012

40. Medical Research Council: (2008). Developing and evaluating complex interventions: new guidance. Available at: www.mrc.ac.uk/ complexinterventionsguidance. Accessed Feb 2012.

41. Hilland TA, Beynon C, McGee CE, Murphy RC, Parnell D, Romeo-Velilla M, Stratton G. Foweather L. Training sports coaches to tackle tobacco: formative evaluation of the SmokeFree Sports Campaign. Int J Health Promo and Educ. 2014. doi:10.1080/14635240.2014.915758.

42. Trigwell J, McGee CE, Foweather L. SmokeFree Sports. School Pilot (October 2012). Liverpool John Moores University; 2012.

43. Gray CM, Hunt K, Mutrie N, Anderson AS, Leishman J, Dalgamo L, et al. Football fans in training: the development and optimization of an intervention delivered through professional sports clubs to help men lose weight, become more active and adopt healthier eating habits. BMC Public Health. 2013. doi:10.1186/147-2458-13-232.

44. Public Health England. Health profiles. 2013. Available at: http://www.apho.org.uk. Accessed Sep 2013

45. The Index of Multiple Deprivation 2010: A Liverpool Analysis. 2011. Available at: http://liverpool.gov.uk/council/key-statistics-and-data/indices-ofdeprivation/. Accessed Aug 2012

46. Office for National Statistics. 2011. Available at: http://www.ons.gov.uk/ons/ guide-method/census/2011/index.html. Accessed Sep 2012.

47. Foweather L, Trigwell T, McGee CE. SmokeFree Sports Final Project Report. Liverpool: Liverpool John Moores University: 2014.

48. Trigwell J, McGee CE, Casstles H, Murphy RC, Porcellato LA, Ussher M, et al. Preventing smoking among nine to ten year old children using a novel school-based physical activity intervention. Overview of SmokeFree Sports Educ Health. 2014;32:3.

49. Sallis. JF, Owen N. Ecological models of health behaviour. In Glanz K, RImer BK, Viswanath K (Eds.) Health behaviour and health education: Theory, research and practice. San Francisco: Jossey-Bass.

50. Janz NK, Becker MH. The health belief model: A decade later. Health Educ Quartley. 1984;11(1):1-47.

51. Bandura, A. Social foundations of thought and action: A social cognitive theory. 1986. Prentice-Hall series in social learning theory.

52. Michie S, Richardson M, Johnston M, Abraham C, Hardeman W, et al The behaviour change technique taxonomy (v1) of 93 hierarchically clustered techniques: building an international consensus for the reporting of behaviour change interventions. Annals Behav Med. 2013; 46(1):81-95. doi:10.1007/s12160-01309486-6.

53. Department for Education 2013. The National Curriculum in England: Key stages in 1 and 2 framework document. Available at: https://www.gov.uk/ government/uploads/system/uploads/attachment_data/file/260481/ PRIMARY_national_curriculum_11-9-13_2.pdf. Accessed Feb 2014.

54. de Vries H, Dijkstra M, Kuhuman P. Self-efficacy: the third factor besides attitude and subjective norm as a predictor of behavioural intentions. Health Educ. 1988;3:273-83.

55. Engels RC, Knibbe RA, Drop MJ, de Haan YT. Homogeneity of cigarette smoking within peer groups: influence or selection? Health Educ Behav. 1997;24(6):801-11.

56. World Health Organisation (WHO), Centre for Disease Control (CDC). The Global Youth Tobacco Survey, 2008. Available at: http://www.cdc. gov/mmwr/preview/mmwrhtml/ss5701a3.htm. Accessed Feb 2012

57. National Health Service Information Centre: Health Survey for England Healthy lifestyles, knowledge, attitudes and behaviour. 2007. Available at: http://www.hscic.gov.uk/pubs/hse07healthylifestyles. Accessed Feb 2012.

58. Moore JB, Yin Z, Hanes J, Duda J, Gutin B, Barbeau P. Measuring enjoyment of physical activity in children: Validation of the Physical Activity Enjoyment Scale. J Applied Sport Psychol. 2009;21(S1):S116-29.

59. Bailey SR, Hagen SA, Jeffery CJ, Harrison CT, Ammerman S, Bryson SW, Killen DT, Robinson TN, Killen JD. A randomized clinical trial of the efficacy of extended smoking cessation treatment for adolescent smokers. Nic Tob Res. 2013;15(10): 1655-62.

60. Rosenberg MJ, Hovland Cl, McGuire WJ, Abelson RP, Brehm JW. Attitude organisation and change: An analysis of consistency among attitude components. New Haven: Yale University Press; 1960.

61. Klesges RCm Meyers AW, Klesges LM, La Vasque ME. Smoking, body weight, and their effects on smoking behaviour: a comprehensive review of the literature. Psychol Bull. 1989;106:204-30.

62. Morgan M, Gibbs S, Maxwell K, Britten N. Hearing children's voices: methodological issues in conducting focus groups with children aged 7-11 years. Qualitative Research. 2002; 2(5): doi: 10.1177/1468794102002001636.

63. Epstein I, Stevens B, McKeever P, Baruchel S. Photo Elicitation Interview. (PEI): Using photographs to elicit children perspectives. Int J Qual Methods. 2006; 5(3).

64. Trigwell J, McGee CE, Murphy RC, Porcellato LA, Ussher M, Garnham-Lee K, Knowles ZR, Foweather L. Process evaluation of a sport for health intervention to prevent smoking among primary school children: SmokeFree Sports. BMC Public Health. 2015;15:347.

65. Twisk, JWR. Applied multilevel analysis. Cambridge University Press; 2006.

66. Zhang J, Yu KF. What's the relative risk? A method of correcting the odds ratio in cohort studies of common outcomes. JAMA. 1998;280(19):1690-1.

67. Marshall C, Rossman G.B. Designing qualitative research. 3rd Edition. Sage Publications; 2006

68. Hampson SE, Andrews J, Barckley MA. Predictors of the development of elementary children's intentions to smoke cigarettes: Hostility, prototypes and subjective norms. Nicotine Tob Res. 2007;9(7):751-60.

69. Hecht ML, Elek E, Wagstaff DA, Kam JA, Marsiglia F, Dustman P, Reeves L, Harthun M. Immediate and short-term effects of the 5 th grade version of the keepin it REAL substance use prevention intervention. J Drug Educ. 2008;28(8):225-51.

70. Andrews JA, Gordon JS, Hampson SH, Christiansen SM, Gunn B, Solvic P, Severson $\mathrm{H}$. Short-term efficacy of click city tobacco: changing etiological mechanisms related to the onset of tobacco use. J Prev Sci. 2011;12(1):89-102.

71. Andrews JA, Gordon JS, Hampson SH, Gunn B, Christiansen SM, Solvic P. Long-term efficacy of click city(r): tobacco: a school-based tobacco prevention program. Nictoine Tob Res. 2014;16(1):33-41. doi:10.1093/ntr/ntt106.

72. O'Neill JM, Clark JM, Jones JA. Promoting mental health and preventing substance abuse and violence in elementary students: a randomized control study of the Michigan Model for Health. J Sch Health. 2011;81(6): 320-30. doi:10.1111/j.1746-1561.2011.00597.x.

73. Crone MR, Spruit R, Dijkstra NS, Willemsen MC, Paulussen TGWM. Does a smoking prevention programme in elementary schools prepare children for secondary school? J Preventative Med. 2011;52(1):53-9.

74. Porcellato L, Dugdill L, Springett J. Using focus groups to explore children's perceptions of smoking: reflections on practice. J Health Educ Pract. 2002; 102(6):310-20

75. Topa G, Moriano JA. Theory of Planned Behaviour and smoking: metaanalysis and SEM model. Subst Abuse Rehab. 2010;1:23-33.

76. James DCS, Chen WW, Lindsey R. Evaluation of a tobacco prevention curriculum for elementary school children. Health Educ. 2003;35(2):3-8.

77. Hopfer S, Shin Y, Davis D, Elek E, Kam JA, Hecht ML. A review of elementary school-based substance use prevention programs: Identifying program attributes. J Drug Educ. 2010;40(1):11-36.

78. Isensee B, Hansen J, Maruska K, Hanewinkel R. Effects of a school-based prevention programme on smoking in early adolescence: a 6-month follow-up of the Eigenstndig werden cluster randomised trial. BMJ. 2013. doi:10.1136/bmjopen-2013-00422.

79. Thomas RE, McLellan J, Perera R. School-based programmes for preventing smoking (Review). Cochrane Library. 2013;5:1-331.

80. Hiemstra M, Otten R, de Leeuw RNH, van Schayck OCP, Engels RCME. The changing role of self-efficacy in adolescent smoking initiation. J Adolesc Health. 2011;48(6):597-603.

81. Hiemstra M, Otten R, van Schayxk OCP, Engels RCME. Smoking-specific communication and children's smoking onset: An extension of the theory of planned behaviour. J Psych Health. 2012;27(9):1100-17.

82. Kobus K. Peers and adolescent smoking. J Addict. 2003;98(1):37-55.

83. Bandura A. Self-efficacy: Toward a unifying Theory of Behavioural Change. Psychol Review. 1977:84(2):191-2115.

84. Otten R, Engels R, van de Ven M, Bricker JB. Parental smoking and adolescent smoking stages: The role of parents' current and former smoking, and family structure. J Behav Med. 2007;30:143-54. 
85. Standard Evaluation Framework for physical activity interventions. National Obesity Observatory, 2012 Available at: https://www.noo.org.uk/core/ frameworks/SEF_PA. Accessed Sept 2014.

86. Ringwalt $\mathrm{CL}$, Ennett ST, Holt KD. Drug prevention in elementary schools: an introduction to the special issue. J Drug Educ. 2010;40(1):1-9.

87. Brener ND, Billy JO, Grady WR. Assessment of Factors Affecting the Validity of Self-Reported Health-Risk Behaviour Among Adolescents: Evidence From the Scientific Literature, J Adolesc Health. 2003:33(6);436-57.

88. Dolicini MM, Alder NE, Ginsberg D. Factors influencing agreement between self-reports and biological measures of smoking among adolescents. J Res Adolesc. 1996:6(4):515-42.

Submit your next manuscript to BioMed Central and we will help you at every step:

- We accept pre-submission inquiries

- Our selector tool helps you to find the most relevant journal

- We provide round the clock customer support

- Convenient online submission

- Thorough peer review

- Inclusion in PubMed and all major indexing services

- Maximum visibility for your research

Submit your manuscript at www.biomedcentral.com/submit 